\title{
The Effect of Helicobacter pylori Eradication in Patients with Gastroesophageal Reflux Disease: A Meta-Analysis of Randomized Controlled Studies
}

\author{
Yan Zhao Yarui Li Junbi Hu Xin Wang Mudan Ren Guifang Lu Xinlan Lu \\ Dan Zhang Shuixiang He \\ Department of Gastroenterology, First Affiliated Hospital of Xi'an Jiaotong University, Xi'an, China
}

\begin{abstract}
Keywords
Helicobacter pylori eradication - Gastroesophageal reflux disease $\cdot$ Meta-analysis
\end{abstract}

\begin{abstract}
Aim: Helicobacter pylori infection has been established as a definite risk factor for gastric cancer. However, the consequence of $H$. pylori eradication on the progression of gastroesophageal reflux disease (GERD) remains controversial. The purpose of our study was to investigate the relationship between $H$. pylori eradication and the development of GERD. Methods: A comprehensive, English literature search was performed from January 1990 to April 2019. Only randomized controlled trials (RCT) that evaluated the effect of $H$. pylori eradication on GERD were included. Meta-analysis of pooled OR was performed using Review Manger 5.1.7. Results: Seventeen articles with 6,889 subjects (intention-totreat) that fulfilled the inclusion criteria were finally included in the analysis. Of them, 8 RCTs have the similar study design and inclusion criterion, which included patients with H. pylori infection but without GERD at baseline. The OR for the development of erosive GERD after $H$. pylori eradication was 1.67 (95\% Cl 1.12-2.48, $p=0.01$ ). The OR for the development of GERD-related symptoms after H. pylori eradication in eradication group compared with control group was 1.04 (95\% Cl 0.84-1.29, $p=0.71$ ). In addition, 9 RCTs included patients with both baseline $H$. pylori infection and GERD. The
\end{abstract}

OR for the healing rates and relapse rates after H. pylori eradication in the $H$. pylori eradication group vs. control group was $0.92(95 \% \mathrm{Cl} 0.47-1.82, p=0.82)$ and $1.12(95 \% \mathrm{Cl} 0.60$ $2.09, p=0.71$ ), respectively. Conclusions: Our meta-analyses showed $H$. pylori eradication may lead to the development of new erosive GERD. However, eradication of $H$. pylori may affect neither the healing rates nor relapse rates of preexisting GERD.

(c) 2019 S. Karger AG, Basel

\section{Introduction}

Helicobacter pylori, as a kind of human pathogen, have infected an estimated $50 \%$ of the global population [1]. It can lead to loss of gastric glands and increase the risk of dysplasia, gastritis, digestive ulcer, and gastric cancer [2, 3]. Moreover, $H$. pylori infection has been suggested to be associated with other kinds of gastrointestinal cancers. Currently, the "test and treat" approach use a noninvasive test for the detection of $H$. pylori and then it recommends to treat all $H$. pylori positive ulcer and non-ulcer dyspeptic patients $[4,5]$.

Gastroesophageal reflux disease (GERD) is one of the most common upper gastrointestinal disorders worldwide with the typical symptoms of heartburn and regurgitation. It was reported that the prevalence of GERD was $10-20 \%$ in the western world, which was higher than Asia

\section{KARGER}

(c) 2019 S. Karger AG, Basel

karger@karger.com

www.karger.com/ddi
Shuixiang $\mathrm{He}$

Department of Gastroenterology

First Affiliated Hospital of Xi' an Jiaotong University

277 West Yanta Road, Xi'an, Shaanxi 710061 (China)

E-Mail hesx123@126.com 
area [6]. The increased acid secretion after $H$. pylori eradication has been described as worsening aspects of GERD in people who already have a weak lower esophageal sphincter [7]. A systematic review has showed that the prevalence of $H$. pylori infection was significantly lower in patients with than without GERD [8]. However, this conclusion varied among different countries. The severity of GERD has also been reported to be lower in $H$. pylori-infected patients, which suggested that $H$. pylori infection may provide protection against GERD [9]. More importantly, it has been suggested that the incidence of GERD increases after successful eradication of $H$. pylori [10].

Several clinical trials and systematic reviews have investigated the relationship between $H$. pylori eradication and GERD [11-13]. However, the consequences of $H$. $p y$ lori eradication on the progression of GERD still remain undefined, and the results of these published reviews differ from each other. Therefore, we carried out this metaanalysis that included published randomized controlled trials (RCTs) to investigate the relationship between $H$. pylori eradication and the development of GERD.

\section{Methods}

The present meta-analysis was performed according to a protocol determined before the study, including study objective, prespecified eligibility criteria, and methods of statistical analysis. The primary outcome measure was to investigate whether $H$. pylori eradication could lead to erosive GERD and arouse its related symptoms. The secondary outcome measure included the effect of H. pylori eradication on the preexisting GERD.

\section{Eligibility Criteria}

1. The patients of any age were diagnosed with $H$. pylori infection by histological examination, culture, or ${ }^{13} \mathrm{C}$ breath test. We required patients with $H$. pylori infection to have been randomized into at least 2 groups, receiving either $H$. pylori eradication therapy or placebo. The eradication treatment must have been clearly described. After treatment, patients were required to be tested for $H$. pylori eradication.

2. All randomized controlled studies were included; cohort and control studies, regardless of the retrospective or prospective nature of the study, case reports, review articles, abstracts, and commentaries were excluded.

3. Reviews or comments were excluded.

4. Studies that were published as a full article in the English language and have been published in peer-reviewed medical journals.

\section{Search Strategy}

A computer-assisted search of the literature was performed in PubMed and MEDLINE databases from January 1990 to April 2019. Literature search was performed using the following key- words: (Helicobacter pylori or Hp or H. pylori) and (gastroesophageal reflux disease or gastro-oesophageal reflux disease or GERD or GROD or non-erosive reflux disease or heartburn). The last search was performed on April 23, 2019. The reference lists of the included articles were further searched to identify any additional studies.

\section{Data Extraction}

Data extraction and quality control were performed by 2 reviewers. A consensus was achieved through discussion in cases of disagreement. A data extraction sheet was developed that included authors, publication year, country where the study was conducted, type of disease, sample size, proportion of GERD after H. pylori eradication.

\section{Definitions}

GERD was defined as having heartburn or reflux as described by the patients or having endoscopic erosions in the distal esophagus. The later was identified as erosive GERD. Either symptomatic or endoscopic assessment before and after $H$. pylori eradication was required.

\section{Statistical Analysis}

A meta-analysis of pooled ORs (using random effect or fixed effect model when appropriate) was performed using Review Manager Software (Review Manager 5.1.7; Cochrane Collaboration, Copenhagen, Denmark). Random effect model was applied when the $p$ value for the test of heterogeneity was $<0.10$ [14]. Heterogeneity between studies was assessed by using the chi-square test $(p<0.10$ was considered to represent significant statistical heterogeneity) and the $I^{2}$ statistic $\left(I^{2}>50 \%\right.$ was considered as having substantial heterogeneity) [15].

The methodological quality of the included studies was evaluated using the risk of bias tool suggested by the Cochrane Handbook for Systematic Reviews of Interventions [16].

The quality of RCTs was assessed by 2 reviewers by using the Jadad scale for the assessment of clinical trials, which classifies the RCTs with scores ranging between 0 and 7. It is presumed that studies with a quality score $>4$ were considered high quality, and studies with a score of $\leq 4$ were considered low quality [17, $18]$.

\section{Results}

As shown in Figure 1, our initial search identified 1,945 studies by electronic and hand search initially. Of these, 1,928 were excluded and 17 articles with 6,889 subjects (intention-to-treat) that fulfilled the inclusion criteria were finally included in the analysis. Most of the trials were conducted in western countries; only 3 of them were from Asian areas. Table 1 shows the characteristics of the included studies in each trial. The risk of bias in these included RCTs was shown in online supplementary Figure 1 (for all online suppl. material, see www.karger.com/ doi/10.1159/000504086). The quality score of RCTs ac- 


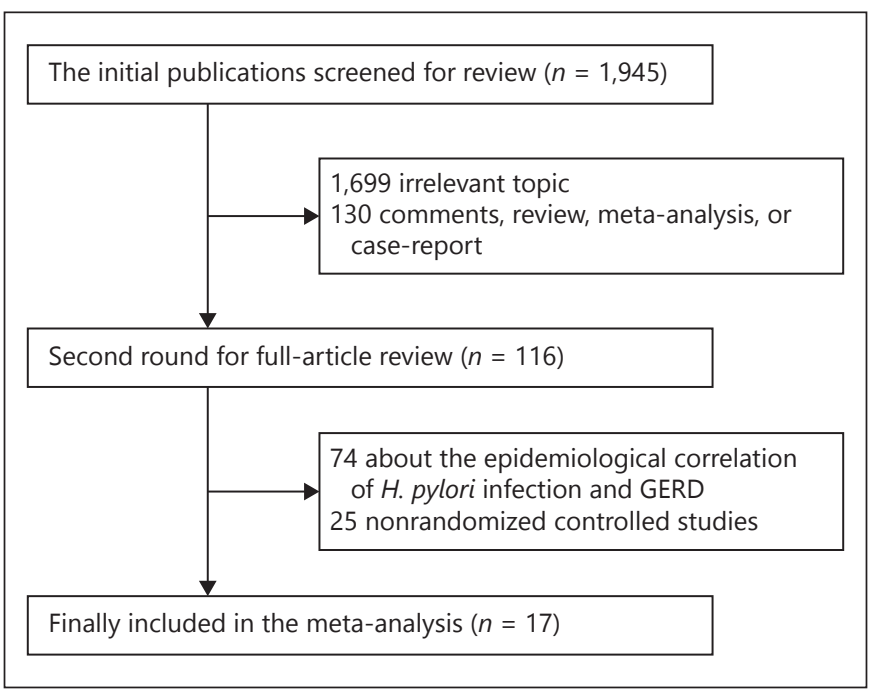

Fig. 1. Study recruitment flowchart. GERD, gastroesophageal reflux disease.

cording to Jadad scale ranged from 3 to 7 with a mean score of 5 . The follow-up time varied from 3 to 30 months. Out of 17 included studies, 8 RCTs have the similar study design and inclusion criterion, which included patients with $H$. pylori infection but without GERD at baseline. Two of them only excluded erosive GERD but included nonerosive GERD. In addition, 9 RCTs included patients with both baseline $H$. pylori infection and GERD. To reflect the effect of $H$. pylori eradication on GERD, we analyzed the results separately according to the inclusion criterion at baseline.

\section{Baseline with $\mathrm{H}$. pylori Infection but without Erosive GERD}

This analysis included 7 RCTs with a total of 2,555 study subjects. The OR for the development of erosive GERD after $H$. pylori eradication in eradication group compared with control group was 1.67 (95\% CI 1.12$2.48, p=0.01$ ). Test of heterogeneity was not significant for the meta-analysis $\left(p=0.78, \chi^{2}=3.21, \mathrm{df}=6, I^{2}=0 \%\right)$. Figure 2 showed this meta-analysis. Sensitivity analysis by sequential exclusion of individual studies did not significantly alter the corresponding pooled results or heterogeneity statistics (online suppl. Table 1). Hence, the results in these studies were validated as relatively stable and credible. The publication bias was assessed using funnel plot. The bilateral symmetry shaped funnel plot did not suggest significant possibility of publication bias (online suppl. Fig. 2a).

H. pylori Eradication in Patients with GERD
Baseline with $\mathrm{H}$. pylori Infection but without Erosive or Nonerosive GERD

This analysis included 5 RCTs with a total of 1,908 study subjects. The OR for the development of GERDrelated symptoms after $H$. pylori eradication in eradication group compared with control group was 1.04 (95\% CI $0.84-1.29, p=0.71$ ). Test of heterogeneity was not significant for the meta-analysis $\left(p=0.38, \chi^{2}=4.23, \mathrm{df}=4\right.$, $\left.I^{2}=5 \%\right)$. Figure 3 showed this meta-analysis. Sensitivity analysis by sequential exclusion of individual studies did not alter the corresponding pooled results (online suppl. Table 2). Hence, the results in these studies were validated as relatively stable and credible. The publication bias was assessed using funnel plot. The bilateral symmetry shaped funnel plot indicated low possibility of publication bias (online suppl. Fig. 2b).

\section{Baseline with both GERD and $\mathrm{H}$. pylori Infection}

Nine studies included both GERD and $H$. pylori infection at baseline. Most of these studies had various study design and endpoints, and finally did not provide detailed information needed for the proposed analysis. Thus, we summarized the characteristics of these studies in Table 2. Of them, 2 RCTs with 196 subjects reported the results about the healing rates of erosive GERD after $H$. pylori eradication. The OR for the healing rates in the $H$. pylori eradication group vs. control group was 0.92 (95\% CI $0.47-$ $1.82, p=0.82)$. Test of heterogeneity was not significant for the meta-analysis $\left(p=0.43, \chi^{2}=0.62, \mathrm{df}=1, I^{2}=0 \%\right.$ ). Figure 4 showed this meta-analysis. In addition, 2 RCTs with 166 subjects reported the results about the relapse rates of GERD after $H$. pylori eradication. The OR for the relapse rates of GERD in the $H$. pylori eradication group vs. control group was 1.12 (95\% CI 0.60-2.09, $p=0.71$ ). Test of heterogeneity was not significant for the meta-analysis $\left(p=0.8, \chi^{2}\right.$ $\left.=0.07, \mathrm{df}=1, I^{2}=0 \%\right)$. Figure 5 showed this meta-analysis.

\section{Discussion}

Although several clinical studies have been conducted to investigate the consequences of $H$. pylori eradication on the symptoms and incidence of GERD, it still remains controversial that whether eradication of $H$. pylori would induce or exacerbate GERD. Several previous reviews have reported the relationship between $H$. pylori eradication and GERD. But the results of these reviews were heterogeneous due to the use of heterogeneous references. The strength of our meta-analysis was that we analyzed the results separately according to the inclusion criterion 
Table 1. Detailed characteristics of the 16 studies included in the meta-analysis

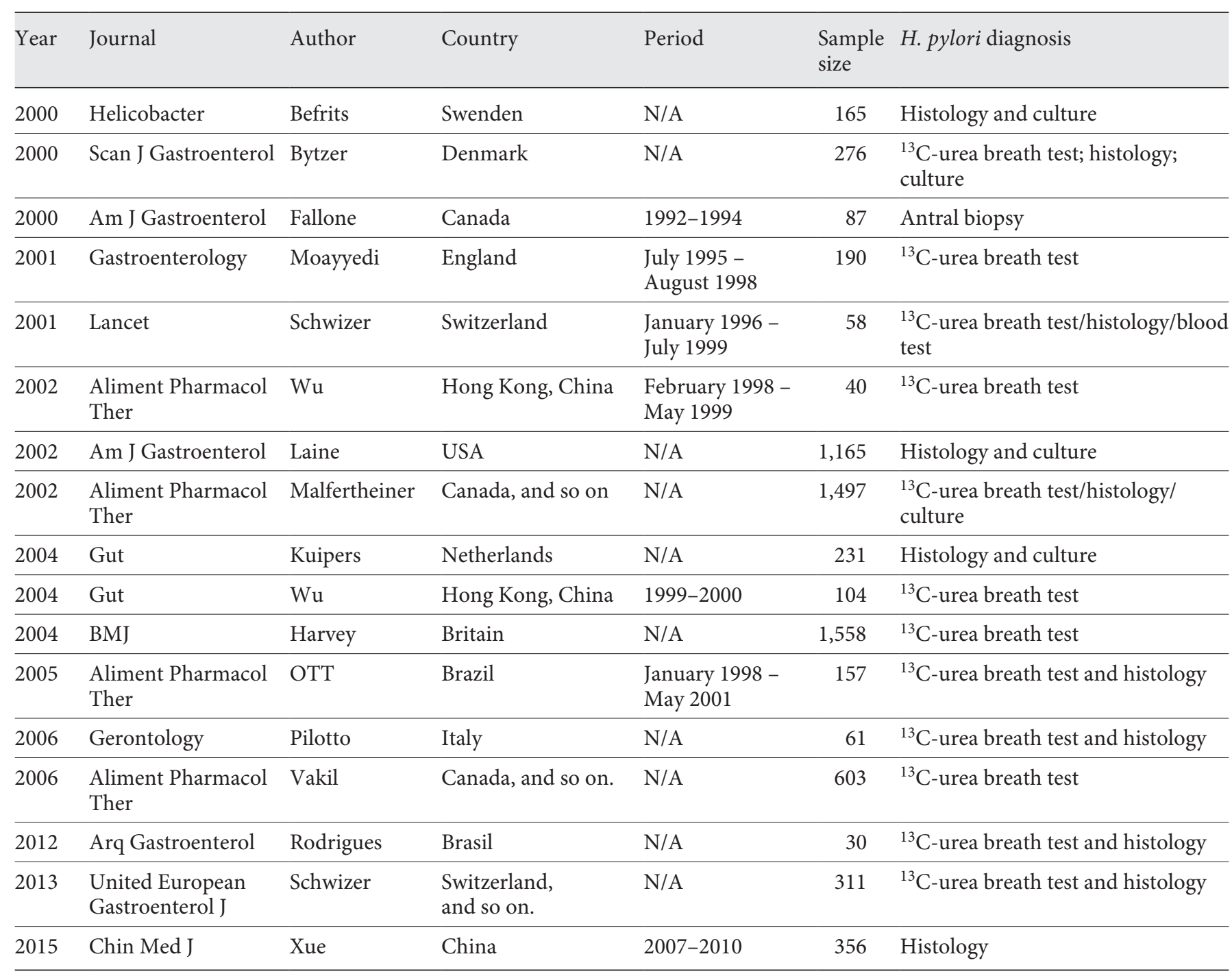

N/A, not available.

at baseline and clearly reflected the effect of $H$. pylori eradication on new or preexisting GERD. The results showed that $H$. pylori eradication may lead to the development of new erosive GERD. It has an approximately twofold increased risk of development of new GERD in patients with eradication of $H$. pylori compared with those without $H$. pylori eradication. However, eradication of $H$. pylori may affect neither the healing rates nor relapse rates of preexisting GERD.

The results of our meta-analysis differ from the published results by Yaghoobi et al. [11], which showed that there is no association between $H$. pylori eradication and development of new cases of GERD in dyspeptic patients. But there was a numerical trend toward significant results for patients with peptic ulcer diseases. This study included 6 RCTs from 1983 to 2007. In our study, we included more RCTs, and the different outcomes may be caused by the later emerging evidence.

Another meta-analysis by Xie et al. [12] showed a negative association with the development of endoscopic GERD, which was consistent with our study. However, there are still several main differences between these 2 meta-analyses. First, the inclusion criteria in our study were RCTs, but the study by Xie et al. [12] included cohort study 


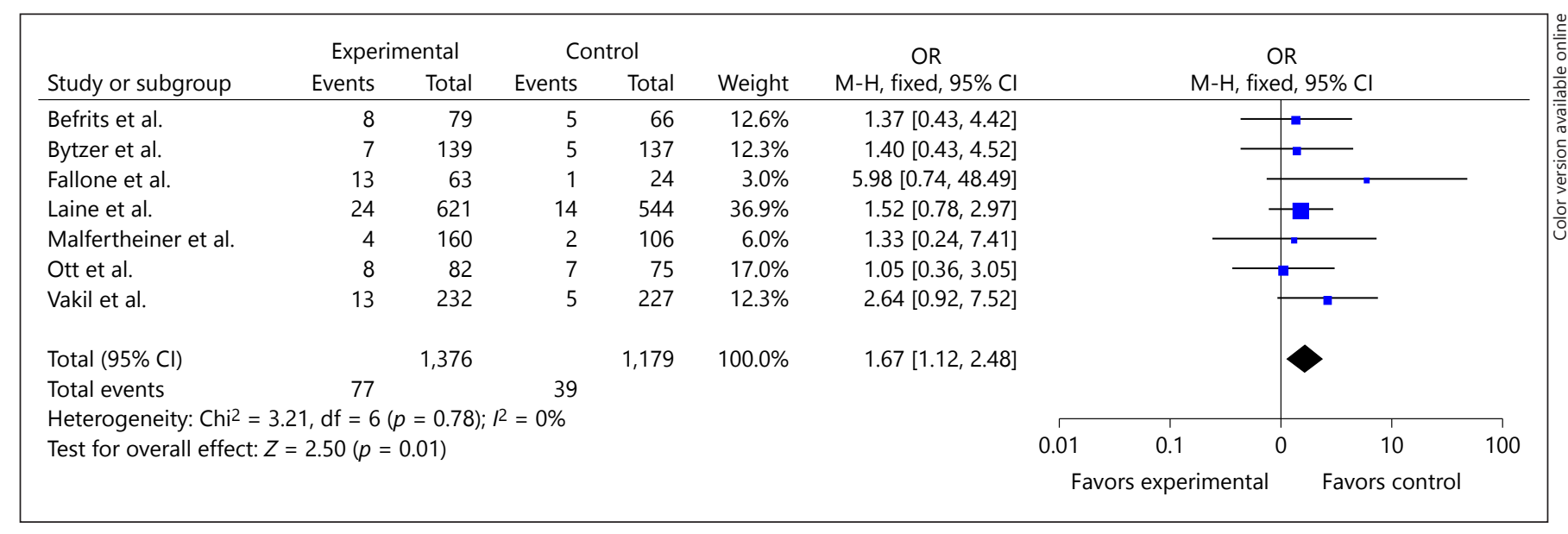

Fig. 2. Forest plot shows the development of erosive GERD after H. pylori eradication in eradication group compared with control group.

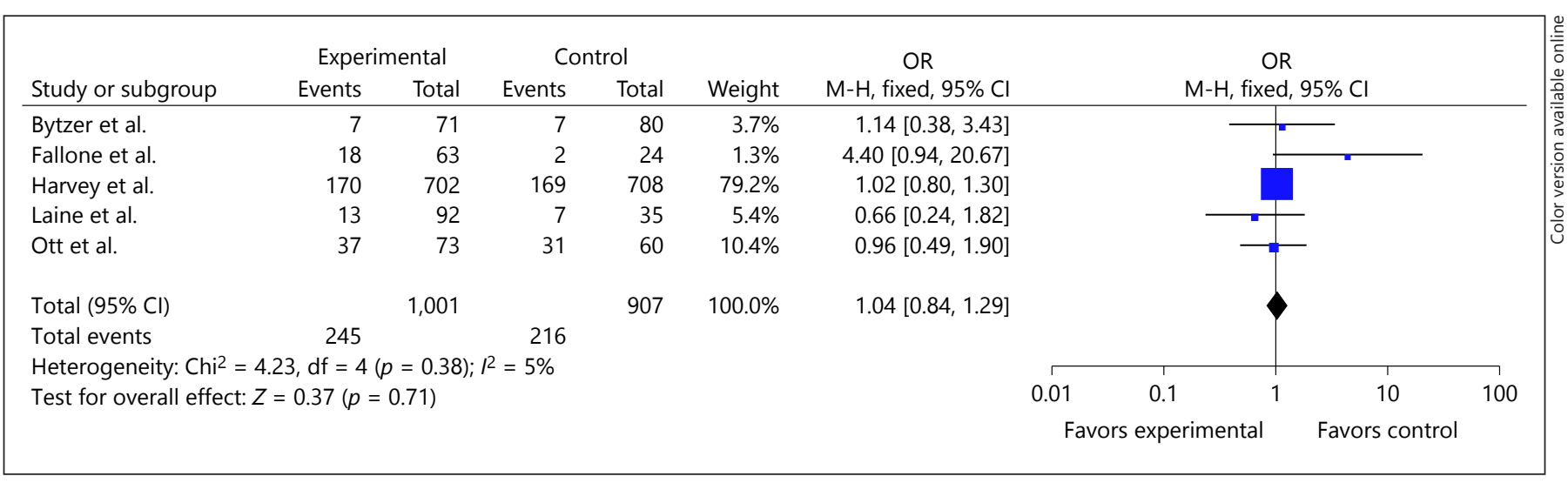

Fig. 3. Forest plot shows the development of GERD-related symptoms after $H$. pylori eradication in eradication group compared with control group.

as well. Second, in the previous study, the meta-analysis included the data from all studies. But it should be noted that these studies have different study design with various inclusion criteria at baseline. We found that currently the clinical studies in this field were mainly designed as 2 types as follows. One kind was to include patients with $H$. pylori infection but without GERD at baseline. And the endpoint was to investigate the development of new erosive GERD or GERD-related symptoms after $H$. pylori eradication. The other kind was to include patients with both $H$. pylori infection and GERD at baseline. And the endpoint was to observe whether $H$. pylori eradication could affect the preexisting GERD relapse or healing rates. Our meta-analysis separately summarized these studies according to their baseline design and finally identified 8 in the former type and 9 RCTs in the later type. The results showed an increased risk for development of new erosive GERD after $H$. pylori eradication. However, eradication treatment may not worsen preexisting GERD or affect its healing rates.

The reasons that $H$. pylori eradication may exaggerate the symptoms of GERD or cause erosive GERD were as follows. First, $H$. pylori infection may enhance the treatment of proton pump inhibitors to reduce acidity. However, rebound acid hypersecretion has been observed in $H$. pylori-negative patients after stopping proton pump inhibitor therapy $[19,20]$. Second, H. pylori-derived antritis is associated with hypergastrinemia with consequent gastric hyperacidity which may aggravate GERD [21,22]. The Maastricht V/ Florence Consensus Report discussed the relationship between $H$. pylori and GERD [23]. The 
Table 2. The characteristics of studies included both GERD and Helicobacter pylori infection at baseline

\begin{tabular}{|c|c|c|c|c|c|}
\hline Year & Author & Primary endpoint & Secondary endpoint & Definitions & Conclusion \\
\hline 2001 & Schwizer & Time to relapse & N/A & $\begin{array}{l}\text { A relapse was defined as recurrence } \\
\text { of GERD symptoms to pre-study } \\
\text { symptom score or a score } \\
\text { corresponding with mild to } \\
\text { moderate symptoms at least twice a } \\
\text { week }\end{array}$ & $\begin{array}{l}\text { H. pylori-positive patients relapsed } \\
\text { earlier than did those in whom } \\
\text { H. pylori was eradicated }\end{array}$ \\
\hline 2001 & Moayyedi & $\begin{array}{l}\text { Time to first } \\
\text { relapse }\end{array}$ & $\begin{array}{l}\text { Relapse rates at } \\
12-18 \text { months }\end{array}$ & $\begin{array}{l}\text { A relapse was defined as the } \\
\text { recurrence of moderate or severe } \\
\text { GERD symptoms for } 2 \text { or more } \\
\text { days per week }\end{array}$ & $\begin{array}{l}\text { H. pylori eradication therapy does } \\
\text { not seem to influence relapse rates } \\
\text { in GERD }\end{array}$ \\
\hline 2002 & $\mathrm{Wu}$ & $\begin{array}{l}\text { Esophageal acid } \\
\text { exposure }\end{array}$ & $\begin{array}{l}\text { Reflux symptom } \\
\text { score and grading } \\
\text { of erosive } \\
\text { esophagitis }\end{array}$ & N/A & $\begin{array}{l}\text { H. pylori eradication increases } \\
\text { esophageal acid exposure and may } \\
\text { adversely affect the clinical course } \\
\text { of GERD }\end{array}$ \\
\hline 2004 & Kuipers & $\mathrm{N} / \mathrm{A}$ & $\mathrm{N} / \mathrm{A}$ & N/A & $\begin{array}{l}\text { H. pylori eradication did not } \\
\text { worsen reflux disease }\end{array}$ \\
\hline 2004 & $\mathrm{Wu}$ & $\begin{array}{l}\text { Treatment failure } \\
\text { within } 12 \text { months }\end{array}$ & $\begin{array}{l}\text { Reflux symptom } \\
\text { score }\end{array}$ & $\begin{array}{l}\text { Failure was defined as either } \\
\text { incomplete resolution of symptoms } \\
\text { or esophagitis at the initial } \\
\text { treatment phase or maintenance } \\
\text { phase }\end{array}$ & $\begin{array}{l}\text { H. pylori eradication leads to more } \\
\text { resilient GERD }\end{array}$ \\
\hline 2006 & Pilotto & $\begin{array}{l}\text { Symptoms } \\
\text { improvement and } \\
\text { healing rates of } \\
\text { esophagitis }\end{array}$ & N/A & N/A & $\begin{array}{l}\text { Eradication of } H \text {. pylori does not } \\
\text { affect the clinical outcome of } \\
\text { esophagitis }\end{array}$ \\
\hline 2012 & Rodrigues & $\begin{array}{l}\text { Symptoms } \\
\text { improvement }\end{array}$ & N/A & $\begin{array}{l}\text { Symptom improvement was } \\
\text { defined as at least } 50 \% \text { decrease in } \\
\text { symptom scores }\end{array}$ & $\begin{array}{l}\text { H. pylori eradication does not } \\
\text { influence GERD }\end{array}$ \\
\hline 2013 & Schwizer & $\begin{array}{l}\text { Time to } \\
\text { symptomatic } \\
\text { relapse }\end{array}$ & $\begin{array}{l}\text { The effect of } \\
\text { eradication on } \\
\text { reflux esophagitis }\end{array}$ & $\begin{array}{l}\text { Relapse was defined as recurrence } \\
\text { of GERD symptoms to an Eraflux } \\
\text { score of } 25\end{array}$ & $\begin{array}{l}\text { H. pylori eradication had no effect } \\
\text { on symptomatic relapse }\end{array}$ \\
\hline 2015 & Xue & $\begin{array}{l}\text { Healing rate of } \\
\text { reflux esophagitis } \\
\text { and remission of } \\
\text { reflux symptoms }\end{array}$ & N/A & N/A & $\begin{array}{l}\text { H. pylori eradication have no } \\
\text { significant effect on GERD }\end{array}$ \\
\hline
\end{tabular}

N/A, not available; GERD, gastroesophageal reflux disease.

increased acid secretion after $H$. pylori eradication has been confirmed, particularly for the patients with GERD who already have a weak lower esophageal sphincter. In statement 9 of this consensus, it was suggested that eradication of $H$. pylori on average neither causes nor exacerbates GERD though $H$. pylori and GERD are negatively associated [24]. However, it also admitted that the level of evidence to support this view was low, which means more strong evidence is needed to explore this issue.
Our meta-analysis has certain limitations. First, there was the probability of publication bias. We have tried to minimize this bias by searching all relevant studies online sources. It was still possible that some unpublished data or articles in non-English language were missed. However, Moher et al. [25] suggested that an English language restriction would not result in too larger bias. Second, in the present included RCTs, some of them did not provide detailed information to for the proposed analysis. Thus, 


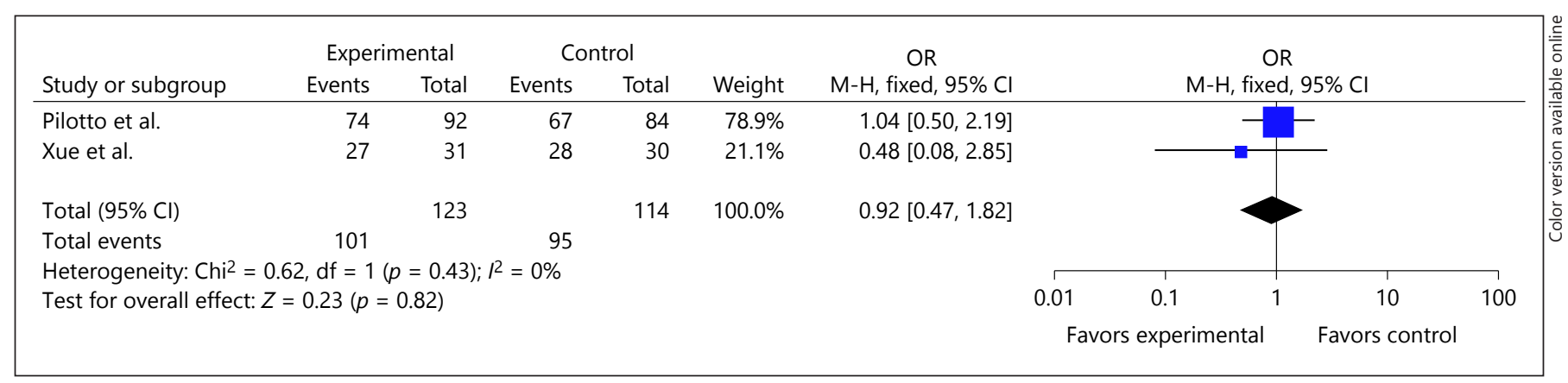

Fig. 4. Forest plot shows the healing rates of GERD in the H. pylori eradication group vs. control group.

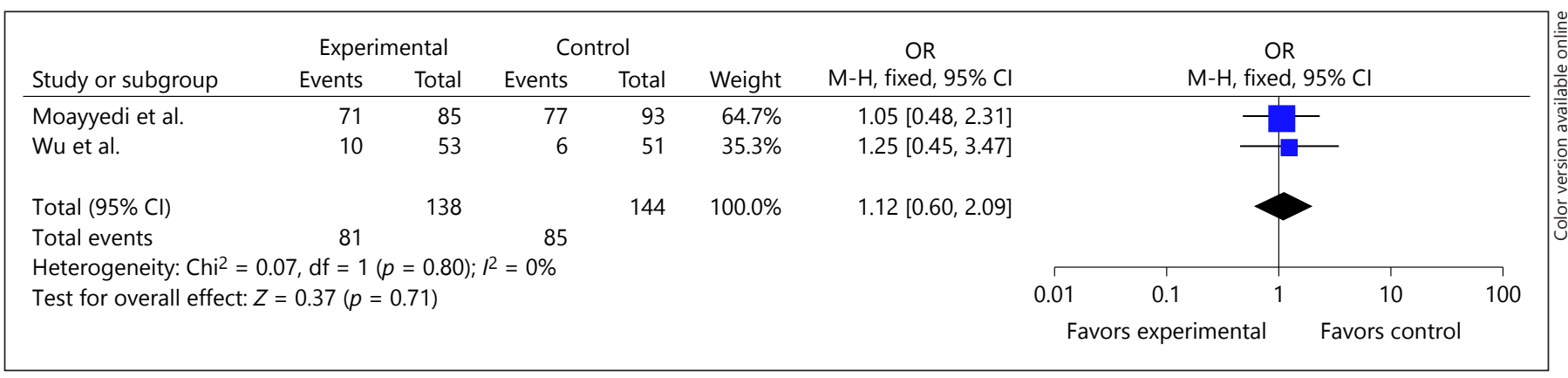

Fig. 5. Forest plot shows the relapse rates of GERD in the H. pylori eradication group vs. control group.

we could only list the outcomes of these studies. Third, the included 17 RCTs used different eradication regimens. Most of them used triple methods including amoxicillin, clarithromycin, and esomeprazole. But the treatment period was different among different studies that ranged from 1 week to 14 days, which may potentially affect the eradication rate and finally caused outcomes bias. Moreover, irrespective of posteradication, $H$. pylori status could raise the question of heterogeneity. After all, it is possible than the results about the comparison between $H$. pylori eradication and control groups may differ from the comparison between eradication success group and failure group.

In conclusion, our meta-analysis showed that eradication of $H$. pylori increased risk of development erosive GERD compared with those without eradication. In future, well-designed RCTs from Asian countries with longterm follow-up period are needed. Particularly, the studies about the effect of $H$. pylori eradication on preexisting GERD are needed to provide more detailed information. In addition, it is important to separate the baseline reflux symptoms from the new emerging reflux symptoms after $H$. pylori eradication in the outcome analysis.

\section{Statement of Ethics}

This is a meta-analysis and therefore the ethical approval was not required.

\section{Disclosure Statement}

The authors have declared no conflicts of interest.

\section{Funding Sources}

This study was supported by National Natural Science Foundation of China with the grant number 81900489 .

\section{Author Contributions}

Y.Z. and S.H.: conceived and designed the study; Y.Z., Y.L., J.H., X.W., and D.Z.: collection and analysis of data; all authors: manuscript writing; M.R., G.L., X.L., and S.H.: critical revision of the manuscript. All authors approved the final manuscript submitted. 


\section{References}

1 Malfertheiner P, Megraud F, O'Morain CA, Atherton J, Axon AT, Bazzoli F, et al.; European Helicobacter Study Group. Management of Helicobacter pylori infection-the Maastricht IV/ Florence Consensus Report. Gut. 2012 May;61(5):646-64.

2 Kuipers EJ, Uyterlinde AM, Peña AS, Roosendaal R, Pals G, Nelis GF, et al. Long-term sequelae of Helicobacter pylori gastritis. Lancet. 1995 Jun;345(8964):1525-8.

3 Ekström AM, Held M, Hansson LE, Engstrand L, Nyrén O. Helicobacter pylori in gastric cancer established by CagA immunoblot as a marker of past infection. Gastroenterology. 2001 Oct;121(4):784-91.

4 European Helicobacter Pylori Study Group. Current European concepts in the management of Helicobacter pylori infection. The Maastricht Consensus Report. Gut. 1997 Jul; 41(1):8-13.

5 Fallone CA, Barkun AN, Friedman G, Mayrand S, Loo V, Beech R, et al. Is Helicobacter pylori eradication associated with gastroesophageal reflux disease? Am J Gastroenterol. 2000 Apr;95(4):914-20.

6 Dent J, El-Serag HB, Wallander MA, Johansson S. Epidemiology of gastro-oesophageal reflux disease: a systematic review. Gut. 2005 May;54(5):710-7.

7 Fukuchi T, Ashida K, Yamashita H, Kiyota N, Tsukamoto R, Takahashi $\mathrm{H}$, et al. Influence of cure of Helicobacter pylori infection on gastric acidity and gastroesophageal reflux: study by $24-\mathrm{h} \mathrm{pH}$ monitoring in patients with gastric or duodenal ulcer. J Gastroenterol. 2005 Apr;40(4):350-60.

8 Raghunath A, Hungin AP, Wooff D, Childs S. Prevalence of Helicobacter pylori in patients with gastro-oesophageal reflux disease: systematic review. BMJ. 2003 Apr;326(7392):737.

9 McColl KE. Clinical practice. Helicobacter pylori infection. N Engl J Med. 2010 Apr; 362(17):1597-604
10 Labenz J, Blum AL, Bayerdörffer E, Meining A, Stolte M, Börsch G. Curing Helicobacter pylori infection in patients with duodenal ulcer may provoke reflux esophagitis. Gastroenterology. 1997 May;112(5):1442-7.

11 Yaghoobi M, Farrokhyar F, Yuan Y, Hunt $\mathrm{RH}$. Is there an increased risk of GERD after Helicobacter pylori eradication?: a meta-analysis. Am J Gastroenterol. 2010 May;105(5): 1007-13; quiz 1006, 1014.

12 Xie T, Cui X, Zheng H, Chen D, He L, Jiang B. Meta-analysis: eradication of Helicobacter pylori infection is associated with the development of endoscopic gastroesophageal reflux disease. Eur J Gastroenterol Hepatol. 2013 Oct;25(10):1195-205.

13 Qian B, Ma S, Shang L, Qian J, Zhang G. Effects of Helicobacter pylori eradication on gastroesophageal reflux disease. Helicobacter. 2011 Aug;16(4):255-65.

14 Hatala R, Keitz S, Wyer P, Guyatt G; Evidence-Based Medicine Teaching Tips Working Group. Tips for learners of evidencebased medicine: 4 . Assessing heterogeneity of primary studies in systematic reviews and whether to combine their results. CMAJ. 2005 Mar;172(5):661-5.

15 Higgins JP, Thompson SG, Deeks JJ, Altman DG. Measuring inconsistency in meta-analyses. BMJ. 2003 Sep;327(7414):557-60.

16 Higgins JP, Altman DG, Gøtzsche PC, Jüni P, Moher D, Oxman AD, et al.; Cochrane Bias Methods Group; Cochrane Statistical Methods Group. The Cochrane Collaboration's tool for assessing risk of bias in randomised trials. BMJ. 2011 Oct;343:d5928.

17 Jadad AR, Moore RA, Carroll D, Jenkinson C, Reynolds DJ, Gavaghan DJ, et al. Assessing the quality of reports of randomized clinical trials: is blinding necessary? Control Clin Trials. 1996 Feb;17(1):1-12.
18 Bañares R, Albillos A, Rincón D, Alonso S, González M, Ruiz-del-Arbol L, et al. Endoscopic treatment versus endoscopic plus pharmacologic treatment for acute variceal bleeding: a meta-analysis. Hepatology. 2002 Mar;35(3):609-15.

19 Holtmann G, Cain C, Malfertheiner P. Gastric Helicobacter pylori infection accelerates healing of reflux esophagitis during treatment with the proton pump inhibitor pantoprazole. Gastroenterology. 1999 Jul;117(1):11-6.

20 Gillen D, Wirz AA, Ardill JE, McColl KE. Rebound hypersecretion after omeprazole and its relation to on-treatment acid suppression and Helicobacter pylori status. Gastroenterology. 1999 Feb;116(2):239-47.

21 Wu JC, Sung JJ, Ng EK, Go MY, Chan WB, Chan FK, et al. Prevalence and distribution of Helicobacter pylori in gastroesophageal reflux disease: a study from the East. Am J Gastroenterol. 1999 Jul;94(7):1790-4.

22 Labenz J, Malfertheiner P. Helicobacter pylori in gastro-oesophageal reflux disease: causal agent, independent or protective factor? Gut. 1997 Sep;41(3):277-80.

23 Malfertheiner P, Megraud F, O’Morain CA, Gisbert JP, Kuipers EJ, Axon AT, et al.; European Helicobacter and Microbiota Study Group and Consensus panel. Management of Helicobacter pylori infection-the Maastricht V/Florence Consensus Report. Gut. 2017 Jan; 66(1):6-30.

24 Warburton-Timms VJ, Charlett A, Valori RM, Uff JS, Shepherd NA, Barr H, et al. The significance of cagA(+) Helicobacter pylori in reflux oesophagitis. Gut. 2001 Sep;49(3):3416.

25 Moher D, Pham B, Klassen TP, Schulz KF, Berlin JA, Jadad AR, et al. What contributions do languages other than English make on the results of meta-analyses? J Clin Epidemiol. 2000 Sep;53(9):964-72. 